\title{
GARCIA-MORENO RODRIGUEZ, Fernando (Coord.), La despoblación del mundo rural: algunas propuestas (prácticas y realistas) desde los ámbitos jurídico, económico y social para tratar de paliar o revertir tan denostado fenómeno, Navarra, Thomson Reuters Aranzadi, 2019, 571 pp. 209-238. (ISBN: 978-84-1309-578-3).
}

Carlos Alberto Lima de Almeida ${ }^{1}$

Una comparativa fácil entre Brasil y España, en relación a la población, sería la de que tanto en distribución y homogeneidad en la distribución territorial de la población es sustancialmente diferente. Un país como Brasil, con catorce veces la extensión que tiene España, cuenta con cuatro veces el número de habitantes de España, concentrados en su mayoría en las grandes macro urbes de la costa. El interior del país, además de tener una baja densidad poblacional, presenta deficiencias económicas y, por ende, de políticas públicas. En ocasiones es una problemática que parece una espiral: deficientes servicios son los que dificultan fijar población; a la vez, poca población hace que económicamente sea insostenible el mantenimiento de algunos servicios. En Brasil no hay problema demográfico pero sí una clara tendencia a emigrar desde el vasto territorio interior a las macro-urbes alojadas prácticamente todas en la costa atlántica, lo que después se plasma en diferencias y desigualdades de derechos según la determinada zona geográfica donde se resida.

En España se lleva hablando desde hace tiempo acerca del problema de la despoblación en el ámbito rural. Pero hasta la lectura de la obra que estamos ahora reseñando, no se había conocido en toda su magnitud: La despoblación del mundo rural: algunas propuestas (prácticas y realistas) desde los ámbitos jurídico, económico y social para tratar de paliar o revertir tan denostado fenómeno, dirigida por el profesor Fernando García-Moreno Rodríguez.

\footnotetext{
${ }^{1}$ Professor Permanente do Programa de Mestrado e Doutorado em Direito da Universidade Estácio de Sá (PPGDUNESA) e da Graduação em Direito (UNESA). Líder do Grupo de pesquisa Observatório de Políticas Públicas, Direito e Proteção Social. Coordenador do Projeto de Extensão Social Núcleo de Extensão e Pesquisa de Acessibilidade e Inclusão (NEPAI-UNESA). Pós Doutor em Direito, Doutor e Mestre em Política Social, Doutorado em Educação (Em andamento), Mestre em Educação, Especialista em prevenção às drogas e escola, Especialista em Direito Processual Civil, Graduado em Direito. Ministra aulas EaD desde 2012.
} 
De inicio, la obra presenta una gran virtud que no es la de incidir, más que lo imprescindible- en el diagnóstico ya conocido de la despoblación en el mundo rural que está sufriendo España para centrarse en conocer y comprender sus causas y, sobre todo y más importante, proponer algunas estrategias de posibles políticas públicas de repoblación. Por tanto, además de ofrecer un análisis cuidado y riguroso de cómo se ha llegado hasta esta situación, se diferencia de otros muchos estudios que giran sobre la temática en que la obra plantea propuestas. Y no se trata de propuestas utópicas o irrealizables en la práctica sino todas ellas realistas y susceptibles de ejecución. Por tanto, la obra cumple sobradamente las expectativas que cualquier especialista en el tema o lector ávido de un conocimiento preciso sobre el tema esté buscando.

Un total de veinte colaboradores, todos ellos prestigiosos investigadores son los que en las páginas del libro van desgranando cada uno con su respectiva aportación, la clave de los temas. La interdisciplinariedad de los mismos, provenientes de la Geografía, de la Ciencia política, de la Economía y del Derecho, contribuye a que no se trata de un estudio con un enfoque unidireccional sino abierto a los múltiples factores y acusas que afectan de forma directa a los movimientos poblacionales. El libro va precedido de un prólogo muy cuidado, ofreciendo al lector una panorámica de la situación real de la que se parte en el entorno rural haciendo especial hincapié en los datos y cifras que afectan a la provincia de Burgos y a la Comunidad Autónoma de Castilla y León en su conjunto- para después referirse a una valoración del territorio español en su conjunto. Lejos de circunscribirse al ámbito territorial español, analiza las políticas y acciones de la Unión Europea dirigidas a concienciar a los gobiernos nacionales la necesidad de actuar con prontitud.

Sin embargo, los efectos del Covid-19, además de los que se circunscriben exclusivamente al ámbito sanitario, en cuanto al ámbito jurídico han supuesto una alteración de las prioridades jurídico-políticas hasta el momento como era el de diseñar y empezar a trabajar estrategias para frenar la despoblación en el mundo rural. Una vez se supere esa emergencia, se retomará de nuevo el tema. Pero hay que subrayar que esta situación ha tenido la virtualidad de poner en valor el ámbito rural (donde ha habido un número inferior de contagiados y fallecidos que en los núcleos urbanos). Los destinos turísticos también están marcando tendencia de una preferencia por el ámbito rural. 
La obra se estructura en Dos partes. En la Primera Parte titulada "Visión panorámica y análisis del problema de la despoblación en el mundo rural", se ofrece una visión panorámica y análisis del problema de la despoblación en el mundo rural. En la misma se incluyen unos profundos estudios politológicos -como el de Sergio Pérez Castaños-, sociológicos -como el de Mónica Ibáñez Angulo- e histórico-jurídicos, como el del Profesor Emiliano González Díez, "Despoblación, Territorio y Derecho histórico", en el que a partir de la movilidad y despoblación en la historia de España va explicando cómo se ha evolucionado hasta la contemporaneidad de los desplazamientos poblacionales hasta llegar a nuestros días.

Una vez explicado el origen, causas y evolución de los movimientos poblacionales, la Segunda Parte, rotulada "Propuestas de solución realistas que contribuyen a paliar o revertir el fenómeno de la despoblación” se centra en las propuestas de solución realistas que contribuyan a paliar o revertir el fenómeno de la despoblación. Estas propuestas provienen de tres ámbitos clave como son el jurídico, el económico y el social, incluyéndose varias colaboraciones en cada una de ellas.

En las propuestas desde el ámbito jurídico se ofrecen acertadas estrategias, algunas de las cuales ya están reflejando un claro impacto positivo en los núcleos rurales en los que se han implantado. Es el caso de la original propuesta que presenta Nuria Belloso Martín para paliar la despoblación del territorio rural, "El modelo de Destinos Turísticos Rurales Inteligentes a través de las fiestas recreaciones históricas", que tiene la virtualidad de aunar las fiestas y recreaciones históricas, un fenómeno en auge en numerosas localidades, con el turismo inteligente, aprovechando toda la potencialidad que ofrecen las nuevas tecnologías. Si bien las recreaciones históricas aportan la recuperación de la historia de un municipio, se conjugan con fomentar la sociabilidad natural e imprescindible entre los seres humanos - no son pocas las ocasiones en que la soledad y la falta de un proyecto común en pequeños núcleos rurales privan de ese derecho a la felicidad por la que todos suspiran- y el dar a conocer el patrimonio histórico-artístico del municipio.

La continuidad de las explotaciones agrícolas a través de figuras arrendaticias y la diversificación de la actividad en el mundo rural en apoyo de la transición energética constituye la propuesta del reputado especialista del mundo rural y Derecho agrario, José $\mathrm{M}^{\mathrm{a}}$ de la Cuesta Sáenz; la estrategia de asentar población mediante el District Heating \& Cooling de biomasa forestal, derivadas de la explotación forestal de los montes, de Fernando García-Moreno 
Rodríguez, y, del mismo autor, especialista en Derecho urbanístico, la regulación, planeamiento y gestión urbanística como medio estructural para atraer nueva población al mundo rural ponen de manifiesto la excelente combinación de dos estrategias muy bien articuladas como son por un lado, las relativas al aprovechamiento forestal de los montes y, por otro, el planeamiento urbanístico de pequeños municipios. Todas ellas son exponentes de unas propuestas serias, meditadas y viables jurídicamente para llevar a la práctica. La promoción del trabajo a distancia -que a resultas del Covid-19 ha mostrado su amplio potencial- es examinada por Juan José González López. Desde un enfoque eminentemente jurídico, Ángel Villanueva López ofrece "Una revisión de las competencias y funciones de los Juzgados de los pueblos y pequeñas ciudades como aportación a la solución contra la despoblación de la España rural”.

Las propuestas de orden económico se inician con el estudio de David Blanco-Alcántara y Óscar López de Foronda Pérez, a partir del análisis estadístico del caso de Castila y León en cuanto a la despoblación que sirve a los autores para extrapolarlo al resto de la España vaciada. José María Calzada Arroyo analiza la despoblación como un problema de desequilibrio económico.

Por último, las propuestas desde el ámbito social tienen en común aunar elementos relacionados con estrategias de políticas públicas, como la colaboración de José Manuel Canales Aliende; de turismo rural como estrategia de lucha contra la despoblación del interior de España, de Luis Alfonso Hortelano Mínguez; o como la reforma del Senado, que presenta Marta Méndez Juez, como propuesta para mitigar el problema de la despoblación en España.

En definitiva, esta obra abre la puerta a nuevas ideas y propuestas que permitan fijar población y atraer el talento con proyectos dinamizadores a aquellos territorios en peligro de despoblación. La presentación de algunas experiencias que han contribuido a frenar y paliar, en alguna medida, la despoblación junto con estrategias novedosas que aún no se han implantado, aportan no sólo ingredientes de originalidad sino también de imperiosa necesidad para paliar la despoblación en el ámbito rural español y de los que, sin duda, hay mucho que aprender desde otros contextos geográficos.

Esta obra colectiva encaja en una de las misiones principales que tienen ante sí los investigadores como es la transferencia de conocimiento de la Universidad a la sociedad. Y la cumple con creces, brindando a especialistas, a políticos, a gestores de la Administración local, 
así como para el público interesado en general, unas propuestas que sin duda incitan a la reflexión sobre un problema que no es baladí ya que afecta a la generación actual pero principalmente, a las generaciones futuras. Se trata de una aportación estratégica para un problema estratégico, complejo y con muchas aristas. El mundo rural forma parte de nuestro pasado y de nuestro presente y se deben articular las medidas necesarias -como las que acertadamente presentan los colaboradores de esta obra- para que siga también formando parte de nuestro futuro.

Data de Submissão: 30/07/2020

Data de Aceite: 10/08/2020 